\title{
PARTICIPAÇÃO DA GESTÃO PÚBLICA NA FORMAÇÃO DO ECOSSISTEMA EMPREENDEDOR DE IMPERATRIZ-MA
}

Sandna Nolêto De Araújo'

Marcela Barbosa De Moraes ${ }^{1}$

Ricardo Ferreira Bruno²

Quesia Postigo Kamimura ${ }^{1}$

\footnotetext{
${ }_{1}^{1}$ Programa Pós-Graduação em Gestão e Desenvolvimento Regional / Departamento de Gestão e Negócios / Universidade de Taubaté (UNITAU)

${ }^{2}$ UNITAU - Universidade de Taubaté
} 


\section{PARTICIPAÇÃO DA GESTÃO PÚBLICA NA FORMAÇÃO DO ECOSSISTEMA EMPREENDEDOR DE IMPERATRIZ- MA}

Resumo: O enfoque ecossistêmico permite discernir os atores envolvidos dentro do processo de construção empreendedora e as respectivas participações desses agentes no contexto do empreendedorismo. Diante disto, este artigo tem como objetivo analisar a participação da gestão pública na formação do ecossistema empreendedor de Imperatriz-MA sob a ótica dos seis domínios proposto por Isenberg $(2011 ;$ 2013). Para tanto, o procedimento metodológico foi uma abordagem qualitativa e descritivo e o procedimento de coleta de dados foi por meio de documentos disponíveis em órgãos públicos da cidade. O recorte temporal utilizado no estudo foi dos últimos 10 anos. Observou-se que embora exista um engajamento e esforços direcionados a ações empreendedoras por parte da gestão municipal, ainda é pouco difundida a participação dos agentes públicos para a formação de um ecossistema empreendedor na cidade de Imperatriz-MA, assim como das instituições de ensino superior.

Palavras-chave: Ecossistema Empreendedor. Gestão Pública. Mapeamento. Imperatriz-MA. 


\section{Introdução}

O cenário mundial vem atravessando diversas transformações, como demográficas, sociais e especialmente econômicas em intervalos curtos de tempo, sobretudo, a partir do século $\mathrm{XX}$, pois foi principalmente nesse período, que se começou a intensificação de novas ideias que otimizaram o estilo de vida dos indivíduos. Comumente, essas ideias advêm de inovação, de se fazer algo original ou se posicionar de forma a ter uma visão sob um novo paradigma, mediante ações, serviços ou produtos já existentes, promovendo rupturas significativas ou melhorias substanciais.

Para que essas ideias aconteçam, conta-se com os empreendedores que por sua vez, possuem características muito peculiares, que pensam de maneira excêntrica, que se colocam diante de desafios e se arriscam a inventar o inédito, que exploram novos caminhos e empreendem. Logo, essas particularidades dos empreendedores, precisam ser contempladas e compreendidas pelos indivíduos, uma vez que com o advento da globalização, a concorrência se tornou cada vez mais acirrada e o consumidor ainda mais exigente.

Por muitas décadas, a política econômica direcionou-se fundamentalmente para o apoio às grandes organizações ou grandes grupos econômicos já instituídos, no pensamento de que estas decisivas para o equilíbrio e sustentabilidade econômica. Entretanto, na visão de Carvalho, Viana e Montovani (2016), a realidade e a crise econômica mostram que este modelo despontava falhas e fragilidades com impactos regionais expressivos. Deste modo, pode-se dizer que uma atmosfera econômica adequada ao empreendedorismo está ainda condicionada a existência de organizações jovens e inovadoras, as quais aparecem com maior flexibilidade de adequação a mercados voláteis e maior habilidade e celeridade para reagir à mudança.

O empreendedorismo não pode ser considerado uma saída unânime aos desafios da política econômica. Por esse motivo, acende a abertura para o crescimento econômico e para o melhoramento do bem-estar social regional. Neste cenário, tornou-se notório a importância do ecossistema empreendedor, avaliado como um espaço regional que compreende grande número de interventores institucionais e individuais, promovendo o espectro empresarial, de empreendedorismo e de inovação.

Diante do exposto, este artigo tem como objetivo analisar a participação da gestão pública na formação do ecossistema empreendedor de Imperatriz-MA sob a ótica dos seis domínios proposto por Isenberg $(2011 ; 2013)$.

\section{Referencial Teórico}

\subsection{Ecossistema Empreendedor}

As organizações nascentes necessitam que a atmosfera empresarial ou ambiente a qual estão implantadas, promova suportes que permitam que estas cresçam não apenas quantitativamente, mas que obtenham ganhos qualitativos. Conforme refere Stam (2015) para que o empreendedorismo aconteça numa localidade é preciso que os atores interatuem de forma interdependente. Contudo, o exercício empreendedor é visto, segundo Neck et al., (2004) como uma ação que necessita da dependência de um conjugado de meios que interatuam de maneira

Organizadores:

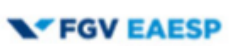

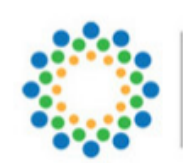

ANEGEPE em Empromingido Estudios de Poquenes Emprome Realizadores:
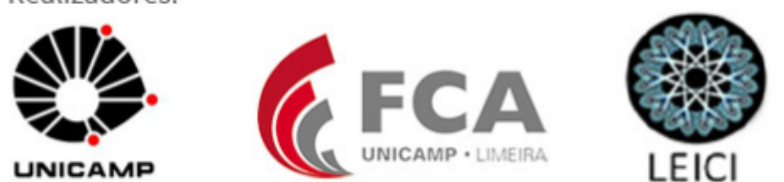
a desenvolver preceitos dinâmicos, capazes de estimular a formação de novas organizações, portanto, este desenho é balizado como "ecossistema de empreendedorismo". Este ecossistema refere-se a:

[...] um conjunto diversificado de atores interdependentes que, dentro de uma região geográfica, influenciam na formação e eventual trajetória de todo o grupo de atores e potencialmente na economia como um todo. Os ecossistemas empreendedores evoluem a partir de um conjunto de componentes interdependentes que interagem para gerar a criação de novos negócios ao longo do tempo (COHEN, 2006, p. 2, 3).

Nesta configuração, os ecossistemas empreendedores consistem em espaços implexos, de estilo cíclico, inovador e enérgico. É valido ratificar, que um ecossistema empreendedor consequentemente, deriva da influência recíproca entre seus envolvidos (atores), os quais evolvem mutuamente e se reforçam de forma conjunta (ISENBERG, 2011).

Proveniente a essas afirmações, os distintos enfoques sobre este contexto é que este estudo se vale e baseia-se no modelo apoiado por Isenberg $(2011 ; 2013)$, que expõe seis importantes domínios inter-relacionados. Assim, a Figura 1, a seguir, apresenta estes domínios aludidos pelo autor:

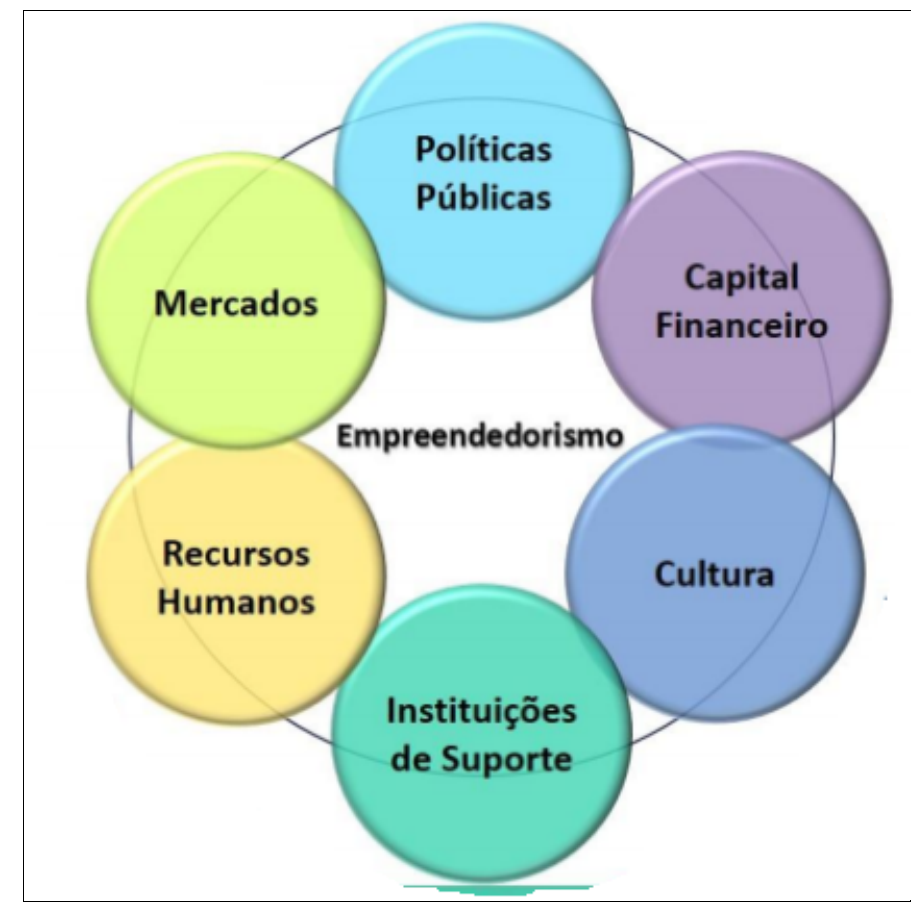

Figura 1: Domínios do Ecossistema Empreendedor Fonte: Isenberg $(2011 ; 2013)$

$\mathrm{O}$ enfoque de ecossistemas empreendedor, consequentemente, observa $\mathrm{o}$ empreendedorismo como uma decorrência do ecossistema e evidencia a acuidade dos empreendedores como condutores na concepção dos ecossistemas e em sustenta-los de forma benéfica (STAM, 2015). Nesse sentido, Mason e Brown (2014), relatam que estes ecossistemas 
se caracterizam por terem operacionalidades locais particulares e arrojos culturais ou predicados físicos que instigam a veleidade das pessoas, particularmente os sujeitos de grupos criativos, em conviverem nestes ambientes.

Logo, faz-se necessário para a compreensão dos ecossistemas de fomento empreendedor a análise vista por os seis aspectos: políticas públicas - na intenção de entender os agentes públicos que impulsionam o empreendedorismo local; Cultura - no intuito de compreender ações desenvolvidas para otimizar a cultura de empreendedorismo, Instituição de Suporte sustentar os novos negócios por meio da relação entre os atores envolvidos e oferta de serviços integrantes, assim, as Instituições de Suporte racionam-se em três grupos: 1.infraestrutura, 2.entidades não governamentais e 3.profissões de apoio e/ou adesão (ISENBERG, 2011). Capital Financeiro - que na visão de Wef (2013), é analisado com um dos três essenciais aspectos do ecossistema empreendedor, vindo, por conseguinte os Mercados e Recursos Humanos, que são peças cruciais para o fomento do ecossistema de empreendedorismo.

Todas as seis dimensões supracitadas corroboram para a composição do ecossistema empreendedor e permitem compreender em amplitude as suas peculiaridades. Por este motivo, optou-se por impetrar a proposta defendida por Isenberg neste referido estudo.

\section{Método de Pesquisa}

As informações disponíveis neste mapeamento do Ecossistema Empreendedor de Imperatriz foram adquiridas por meio de documentos oficias bem como plano diretor, projetos de lei e contratos firmados com alguns parceiros fomentadores do empreendedorismo. Dentro desta análise, foi realizado um escalonamento temporal dos últimos 10 anos, considerando os anos de 2006 a 2017, da gestão pública do município dentro do cenário do ecossistema empreendedor.

Para tanto, adotou quanto à natureza o ecossistema empreendedor do município do Imperatriz, referente ao delineamento da pesquisa o estudo constituiu-se em uma análise de base documental e quanto aos objetivos, análise de caráter descritivo. Uma vez que a intenção foi de trazer representações documentais de cunho relevante dentro deste contexto estudado. Nesse aspecto, os documentos são vistos como acervo de fontes de dados que permitem ao investigador partir para uma pesquisa qualitativa, por isso, precisam de cautela exclusivista ou particular.

Nesse sentido, os documentos compõem-se como fonte "não reativa", ou seja, os subsídios ou informações sobrepujadas conservam-se durante longos anos. O que outrora, pode ser considerado, uma fonte orgânica e correspondente de informações de origem histórica, econômica e social, pois aprovisionam elementos importantes sobre essa mesma conjuntura (GODOY, 1995).

Assim, a pesquisa documental ainda de acordo com Godoy (1995) quando se adequa ao estudo de recorte temporal, objetiva-se investigar uma ou mais convergências (comportamentos e intenções). Ocorre que, a ausência de um modelo padrão e o enredamento da codificação dos dados para muitos investigadores são abalizados como o elemento que traz dificuldade metodológica, exatamente por seu grau de complexidade.
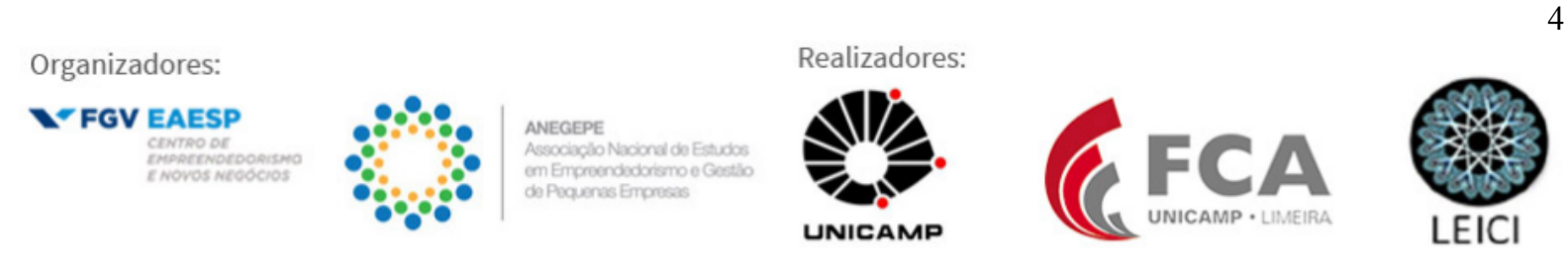
Ainda no que concerne ao delineamento documental e a título de escalonamento temporal, levou-se em consideração, dispositivos legais, como a investigação de projetos de leis, planos diretores, documentos oficiais, circular pública, órgãos como: Associação Comercial de Imperatriz - ACII, Jornal da Imprensa local, Câmara Municipal e a Lei de Licitações Municipais - MPEs. Uma vez que estes são elementos que contém informações pertinentes que evidenciam ou não a participação da gestão pública municipal no fomento ao empreendedorismo de Imperatriz (recorte deste trabalho).

No entanto, para a construção deste trabalho aplicou-se, além disso, a pesquisa descritiva que na vertente de Vergara (2000), exibe atributos ou particularidades de determinada população ou fenômeno, à medida que forma relações entre variáveis, definindo sua natureza. Acrescenta-se também, que este método propende a mapear as particularidades (características) de um conjunto de elementos e constituir relações entre as variáveis ponderadas (BICKMAN; ROG; HEDRICK, 1997). Por conseguinte, adotou-se o critério de análise de conteúdo que segundo a concepção de (BARDIN, 2011, p. 47):

É um conjunto de técnicas de análise das comunicações visando a obter, por procedimentos sistemáticos e objetivos de descrição do conteúdo das mensagens, indicadores (quantitativos ou não) que permitam a inferência de conhecimentos relativos às condições de produção/recepção (variáveis inferidas) destas mensagens.

Corroborando, ainda sobre a análise de conteúdo, na visão de Moraes (1999) compõese em uma técnica de investigação empregada para delinear e interpretar o conteúdo de todo conjunto de documentos e textos. Deste modo, essa apreciação, conduz a uma esquematização sistemática, que pode ser tanto qualitativa quanto quantitativa, auxiliando a reinterpretação das informações, a fim de alcançar uma concepção de seus significados num coeficiente que ultrapassa uma leitura corriqueira.

\section{Resultados e Discussões}

Esta pesquisa foi marcada por aspectos importantes voltados para o mapeamento do ecossistema empreendedor do munícipio de Imperatriz - MA. Ressaltando as iniciativas desenvolvidas da participação do poder público que venha fomentar ações que promovam o empreendedorismo dentro deste cenário.

No intuito de clarificar o estudo, procurou-se trabalhar com os seis pilares do empreendedorismo proposto por Isenberg que foram fundamentais e que serviram de estratégia para a construção deste mapeamento. Sendo eles: 1. Políticas Públicas, 2.Cultura, 3.Capital Financeiro, 4.Instituições de Suporte, 5.Recursos Humanos e 6.Mercados. No entanto, a priori, faz-se necessário compreender as características do ecossistema empreendedor do município, sendo nas sessões posteriores o detalhamento dessas dimensões. Na figura 5 evidencia-se a particularidade deste ecossistema:
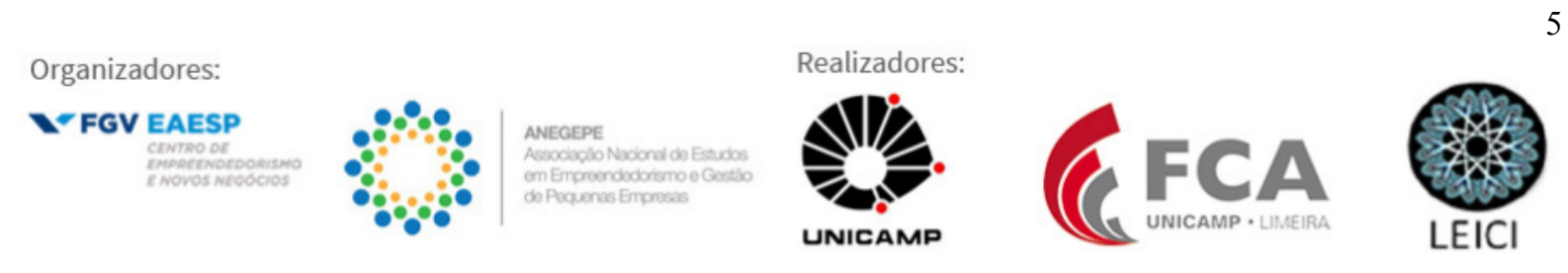


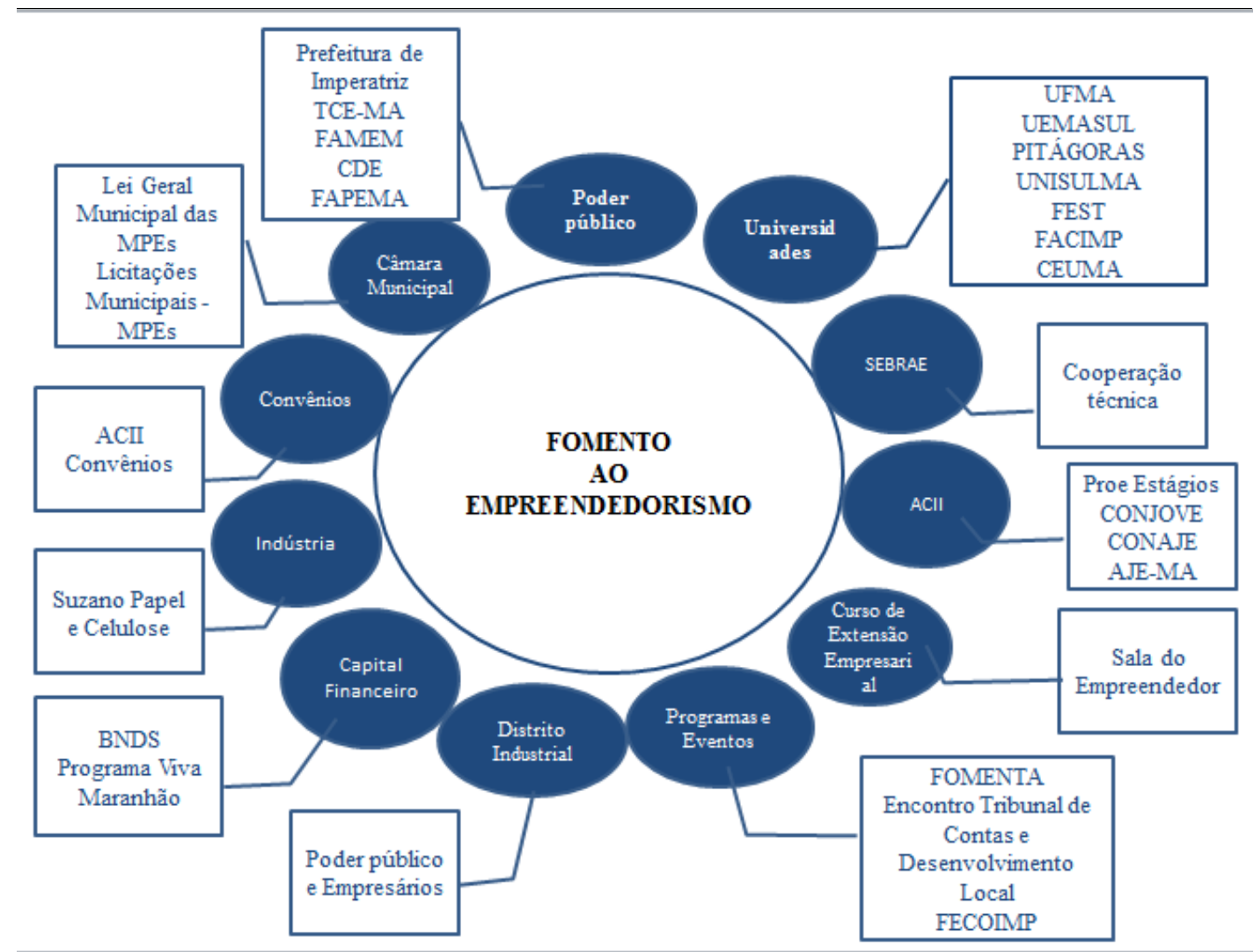

Figura 4: Mapeamento do Ecossistema Empreendedor de Imperatriz - MA.

Fonte: Elaborado pelos Autores

Sabe-se que no empreendedorismo tem-se a inovação, no entanto, o ato de inovar, é muito mais que simplesmente criar novos produtos, a inovação constitui a concepção de novos ajustes entre as esferas institucionais. E nesta configuração tem-se a hélice tripla composta por governo, indústrias e universidades, a qual é considerada o mais eficiente alicerce para o desenvolvimento social e econômico de uma região, ao passo, que a adoção da interação do governo com as demais esferas alarga-se, isto é, desenvolvem-se de forma lateral e verticalmente. Etzkowitz (2005) relata que uma região só se desenvolve potencialmente à medida que cada envolvido (ator) "adota o papel do outro", assim incluem-se as organizações ou empresas hibridas na qual inserem mecanismos que aglomeram os três fomentadores do processo, ou seja, os componentes da hélice tripla.

\section{Políticas Públicas}

Compreende-se que cabe ao gestor público a responsabilidade de planejar, assessorar processos deliberativos, coordenar ações e avaliar programas e políticas públicas em disposições às organizações estatais e não estatais nacionais ou internacionais. Seu desempenho percebido pelos aspectos da União, Estados e Municípios, no qual há uso de expedientes empenhados ou compelidos para a produção de bens públicos. 
Neste prisma, na esfera política, no dia 20 de Dezembro de 2012, o prefeito da gestão anterior do município de Imperatriz Sebastião Madeira, junto com o secretário de Desenvolvimento Econômico - SEDEC Sabino Costa e o gerente do SEBRAE Danilo Lima Lisboa, firmaram oficialmente a instalação da "Sala do Empreendedor" no munícipio de Imperatriz que foi aprovada em 2010, está antevista na Lei Geral Municipal das Micro e Pequenas Empresas (MPEs). Para tanto, em seu discurso Danilo Lima explanou descrevendo:

É uma ferramenta que orientada o poder público no que diz respeito ao apoio a ser dispensado ao empresário no processo de formalização e funcionamento do seu negócio, dentro do regime da figura do empreendedor individual, popularmente conhecida por EI. A "Sala do Empreendedor" será referência única para os microempreendedores de Imperatriz, que receberão orientações técnicas e jurídicas dos agentes de desenvolvimento que atuarão nesse novo espaço na cidade (O PROGRESSO, 2012 p. 1).

A Lei Geral Municipal das Micro e Pequenas Empresas foi sancionada no plenário da Câmara Municipal do munícipio de Imperatriz, que de acordo com o depoimento do prefeito anterior do munícipio Sebastião Madeira, disse que "Em dois anos dentro do seu mandato, já foram criadas 3.700 micro e pequenas empresas em Imperatriz". Ressaltou ainda, expondo que pondera importante a criação da Sala do Empreendedor, pois a mesma terá como objetivo oferecer informações às empresas ou empreendedores que queiram otimizar ou abrir um novo negócio.

Todavia, pode-se afirmar que atualmente A Sala do Empreendedor já é uma concretude em Imperatriz e funciona com eficiência estimulando o empreendedorismo local e dando auxilio para os empreendedores iniciantes.

Não obstante, no dia 10 de Fevereiro de 2017 segundo Edilson Baldez da Neves, presidente do Conselho Deliberativo Estadual - CDE (SEBRAE e FIEMA) as licitações municipais já podem favorecer e/ou beneficiar as micro e pequenas empresas - MPEs.

No entanto, o presidente ao se reportar a prefeitos, vereados e presidentes de câmaras municipais da região no $2^{\circ}$ Encontro de Tribunais de Contas e Desenvolvimento Local, que adveio formado pelo Tribunal de Contas do Estado do Maranhão (TCE-MA), em sociedade com a Federação dos Municípios do Estado do Maranhão (FAMEM) ainda continuou proferindo que:

\begin{abstract}
A lei 123/2006 e seus complementos romperam um paradigma. Antes se acreditava que apenas a lei 8.666/93, que instituiu as formas de licitação, era à base de regulamentação das compras governamentais. Porém, Há quase 11 anos, isso foi ampliado e podemos estimular compras das prefeituras em suas próprias cidades, junto aos pequenos negócios, pelo tratamento diferenciado para as MPEs, o que ajuda a distribuir e fixar riquezas no município. Por isso, me arrisco a dizer que estamos vivendo um momento histórico, onde os esforços do órgão de fiscalização e do SEBRAE convergem para o mesmo objetivo e favorecem a implantação de políticas públicas voltadas para as micro e pequenas empresas (TRIBUNA, 2017, p. 1).
\end{abstract}

A IN 46 aprecia aspectos que avigoram a regulamentação e pratica da Lei Complementar $n^{\circ} 123 / 2006$, que constitui o passadio individualizado ás micro e pequenas empresas nas compras públicas, por meio de objeto de convênios de cooperação, quer seja entre o SEBRAE Nacional, SEBRAE Maranhão e ATRICON - Associação dos Tribunais de Contas, bem como o Tribunal de Contas do Estado - TCE.

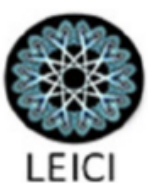




\section{Cultura}

$\mathrm{O}$ atual prefeito Assis Ramos mencionou em uma entrevista ao programa Mirante (filial da rede globo) no dia 30 de Janeiro de 2017 que a parceria com o SEBRAE do Maranhão é relevante para desenvolver a gestão do munícipio de Imperatriz. Salientou ainda dizendo:

Vamos estimular e fomentar a cultura empreendedora em nossa gestão, o SEBRAE será um parceiro forte de nossa gestão na execução e implementação das ações, que irão trazer novos investimentos para Imperatriz e mais alternativas aos nossos pequenos empreendedores, por meio de diversas atividades em parceria com as secretarias (IMIRANTE, 2017).

Nessa vertente, outro suporte a cultura incentivado pela Associação Comercial e Industrial de Imperatriz - ACII conhecido como o Conselho de Jovens Empresários CONJOVE, foi constituído em novembro de 2012, o conselho conta com grupo de jovens empresários do município de Imperatriz, o mesmo tem o objetivo de estimular a cultura empreendedora local entre a juventude. Hoje o CONJOVE é filiado ao Conselho Nacional de Jovens Empresários - CONAJE e a Associação Maranhense de Jovens Empresários - AJEMA. Este mesmo grupo é formado por 18 componentes, solidificando ações direcionadas ao estimulo do empreendedorismo e o fomento de novas lideranças empresariais. Vale ressaltar que em meio aos programas desenvolvidos pela ACII encontra-se o Encontro Maranhense de Jovens Empresários e o Empreendedorismo na Escola (ACIIMA, 2017).

Dentro desse aspecto cultural, foi analisado também, o plano diretor do município de Imperatriz, que segundo o Art. 70 são objetivos da política cultural do município, de acordo com os incisos V - assegurar políticas públicas de cultura com a participação da sociedade; VI - articular política cultural conjugada com outras políticas públicas; VIII - promover o aperfeiçoamento e valorização dos profissionais da área da cultura e dos meios de comunicação. Por conseguinte, no Artigo 71 inciso II menciona - a implantação de programas a formação de estímulos à criação, fruição e participação cultural da sociedade, sobretudo a dos jovens (PLANO DIRETOR MUNICIPAL, 2004).

Contudo, nota-se que a gestão pública poderia concatenar objetivos comuns a estímulos culturais com estímulos empreendedores, haja vista que a população do município em sua grande parte ainda vive do trabalho artesanal movido pela cultura regional ali estabelecida.

\section{Capital Financeiro}

O secretário de Estado de Desenvolvimento, Indústria e Comércio, Maurício Macedo, expôs no dia 18 de setembro de 2014 os empresários da Região Tocantina, o projeto do Distrito Industrial de Imperatriz. O lançamento foi promovido pela Secretaria de Estado do Desenvolvimento, Indústria e Comércio - SEDINC.

Logo, o projeto é considerado um novo arquétipo de infraestrutura produtiva, uma vez que os distritos industriais, que estão sendo implantados de forma pioneira no setor público do Brasil, propõem um conceito contemporâneo de gestão para receber as demandas dos setores da indústria, comércio e serviços e dispõem a atrair distintas organizações para o município de Imperatriz.
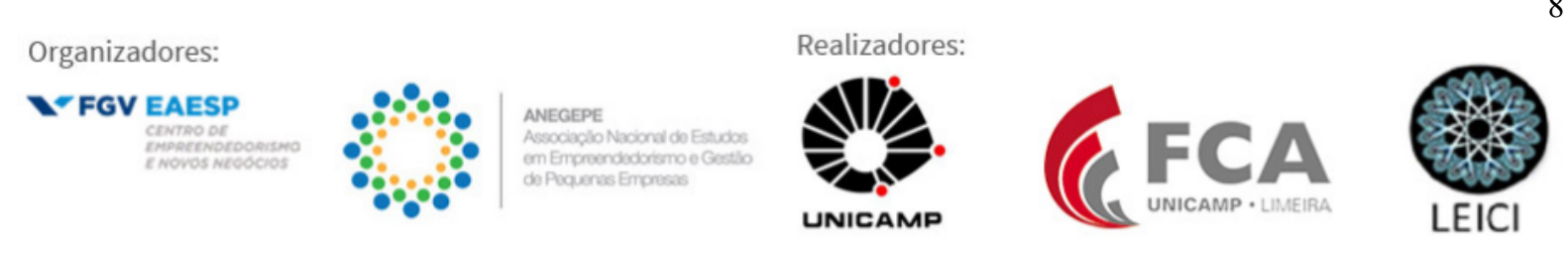
O Distrito Industrial fica situado às margens da BR-010, no quilômetro 268, conexo à rodovia Belém-Brasília, este é composto por uma área integral de um milhão e meio de metros quadrados e é formado por 70 novos lotes empresariais/industriais.

Nesse sentido, a preferência pela munícipio de Imperatriz se deu em decorrência a sua importância econômica, considerada a segunda maior economia do Maranhão, marcado por atividades importantes como a produção de grãos, pecuária, extração de madeira, fábrica de móveis, siderúrgica, geração de energia, florestas de eucalipto e celulose (GOVERNO DO MARANHÃO, 2014).

Segundo o secretário Maurício Macedo, a construção de Distritos Industriais são atuações estratégicas para o desenvolvimento da economia maranhense, na vertente de promover um estado mais dinâmico e com diferencial competitivo, na intenção de atrair novos mercados, bem como novos investimentos, gerando assim, mais emprego e renda. O mesmo acrescenta dizendo que os distritos têm o objetivo de serem administrados por um atualizado conceito de gestão compartilhada entre poder público e empresário, denotando numa parceria pública privada - PPP. O então secretário de Desenvolvimento, Indústria e Comércio, alude que:

Estamos criando uma infraestrutura produtiva moderna que cria um ambiente de negócios favorável à atração de empreendimentos nos municípios, juntamente com os incentivos fiscais que o estado já oferece. O objetivo é dinamizar a economia local, gerar emprego e renda para a população (GOVERNO DO MARANHÃO, 2014).

Vale salientar, que o Distrito Industrial de Imperatriz é formado por lotes difundidos dentro de um espaço urbanizado com ruas pavimentadas organizadas para o trafego de caminhões pesados; avançada sinalização de trânsito horizontal e vertical; ciclovias; pátio de carretas para promover a melhoria logística.

Sobre infraestrutura, esta dispõe de acordo com o Governo do Maranhão (2014) de telecomunicação e internet; sistema de combate a incêndio; equipamentos de vídeo monitoramento com vigilância 24 horas; portaria de controle de acesso de veículos, funcionários e visitantes. Além de contar com o abastecimento de água, energia elétrica, iluminação e drenagem pluvial.

Ainda segundo o Governo do Maranhão (2014) o capital financeiro investido nesse projeto é de R\$ 40 milhões aproximadamente, sendo estes recursos do BNDES, por meio do Programa Viva Maranhão. Contudo, o Distrito Industrial há mais de 20 anos permanecia apenas no papel, hoje pode dizer que é uma realidade existente.

Entretanto, numa outra vertente, foi desenvolvido pela Associação Comercial e Industrial de Imperatriz - ACII visa proporcionar aos associados à instituição ou entidades, funcionários e dependentes acesso a descontos e outros benefícios na aquisição de produtos ou na contratação de serviços das empresas conveniadas.

O ACII CONVÊNIO funciona como uma espécie de shopping de descontos em favor dos que se integrados ao programa de convênio. Deste modo, o ACII Convênio depara reduções na rede de lojas credenciadas para associados, servidores e dependentes que possuem filhos acima de 12 anos e cônjuges das empresas associadas à Associação Comercial e Industrial de Imperatriz (ACIIMA, 2017).
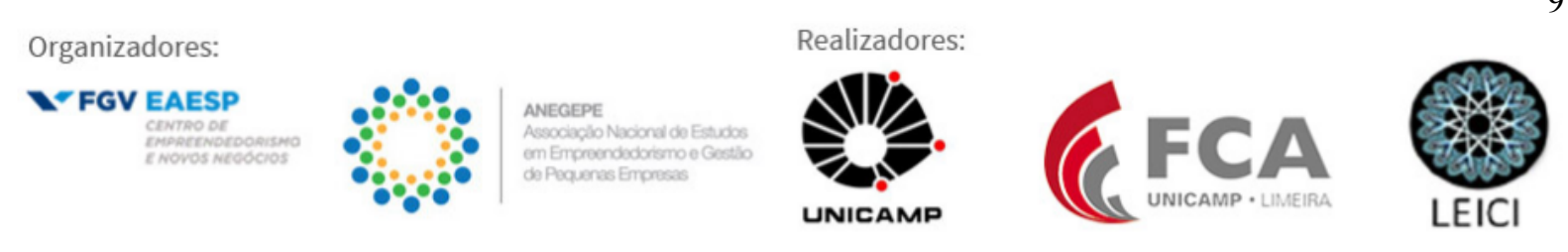


\title{
Instituições de Suporte
}

Concernente as Instituições de Suporte o SEBRAE em parceria com a Prefeitura de Imperatriz assinaram recentemente um termo de cooperação técnica para a realização de ações da instituição em educação empreendedora, políticas públicas para micro e pequenas empresas, ingresso a mercado, apoio para a revisão e atualização da Lei Geral da MPEs municipal, revitalização da Sala do Empreendedor do município e formalização da parceria estratégica para a reformulação do plano estratégico municipal com ênfase nos resultados (IMIRANTE, 2017).

O diretor-superintendente do SEBRAE João Martins em entrevista para o programa local (IMIRANTE, 2017) assegurou:

\begin{abstract}
Nosso objetivo é dar continuidade às parcerias já existentes com o município e oferecer os produtos do SEBRAE disponíveis em seu portfólio, que colaboram para o desenvolvimento do empreendedorismo na cidade de Imperatriz. Já executamos as soluções, como o fomento nas escolas de ações de educação empreendedora. Como a cidade tem regulamentado e implementada a Lei Geral das Microempresas e Empresas de Pequeno Porte, queremos ampliar e investir ainda mais neste aspecto em 2017.
\end{abstract}

O SEBRAE sempre se destaca no que diz respeito a estímulos empreendedores ou ações empreendedoras. Nesse contexto de parcerias para fomentar o ecossistema empreendedor, de acordo com a FIEMA foi criado pelo I Fórum Socioeconômico de Imperatriz, o Comitê Socioeconômico de Imperatriz realizado no dia 23 de maio 2012, instituído por representantes:

[...] da Associação Comercial e Industrial de Imperatriz - ACII, da Federação das Indústrias do Estado do Maranhão - FIEMA, Prefeitura de Imperatriz, SEBRAE, Suzano Papel e Celulose, Faculdade de Imperatriz - FACIMP, da Faculdade de Educação Santa Teresinha - FEST, Unidade de Ensino Superior do Sul do Maranhão - UNISULMA, Faculdade Atenas Maranhense - FAMA (atual PITÁGORAS), $3^{\circ}$ Grupamento Bombeiro Militar - GBM, 50 BIS, Sindicato do Comércio Varejista de Imperatriz, Sindicato das Indústrias de Panificação e Confeitaria de Imperatriz SINPANCIMP, Poder Legislativo, Sindicato das Indústrias e Madeiras de Imperatriz e Região SINDIMIR, Sindicato do Comércio Atacadista - SINDICOMA, Sindicato das Indústrias Metalúrgicas Mecânicas e de Materiais Elétricos de Imperatriz SIMETAL, Sindicato das Indústrias e Reflorestamento para carvão vegetal, e do reflorestamento para celulose dos estados do MA, PI e TO - SICAM, Ministério Público - Promotoria Pública do Consumidor, Sindicato das Indústrias da Construção Civil do Oeste do Maranhão - SINDUSCON, Câmara dos Dirigentes Lojistas de Imperatriz - CDL, Universidade Estadual do Maranhão- UEMA (atual UEMASUL), Universidade Federal do Maranhão - UFMA, Fórum Ministro Henrique De La Roque Almeida, Polícia Militar do Maranhão do $3^{\circ}$ BPM (FIEMA, 2012 p.1).

A intenção do Comitê foi de alçar as indigências latentes da sociedade imperatrizes, propor propostas de melhoria e exigir o desenvolvimento dos projetos expostos junto ao poder público, com o objetivo traçar e discutir sobre: plano diretor e planejamento estratégico de desenvolvimento socioeconômico local.

Outro movimento direcionado para ações ou estímulos empreendedores na região foi promovido em 2011, pela Fundação de Amparo à Pesquisa e ao Desenvolvimento Científico e

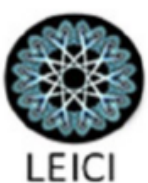


Tecnológico do Maranhão - FAPEMA, participando desta reunião os representantes da diretoria acadêmica da Faculdade de Imperatriz - FACIMP. Na ocasião foram enfatizados sobre os editais direcionados à inovação e empreendedorismo, Programa Pesquisador na Empresa RHAE, bem como o Programa de Apoio à Inovação nas Empresas - PAPPE.

No entanto, A assessora de planejamento da Fundação, Márcia Maciel, deu ênfase aos eventos que a FAPEMA costuma promover como: III Encontro de Inovação do Maranhão e II Mostra Científica do Maranhão. A mesma ampliou o convite à participação para a comunidade acadêmica da região Tocantina (faculdades e universidades). A assessora aludiu também que a FACIMP gerasse atividades em seu campus durante a Semana Nacional de Ciência e Tecnologia 2011. Pois a "A ideia do evento é também descentralizar ações da capital, interiorizando as atividades" (FAPEMA, 2011).

\section{Recursos Humanos}

O Instituto Proe criou o Programa de Complementação Educacional - PROE ESTÁGIOS, que permite as empresas sejam elas públicas ou privadas e profissionais liberais a contratação de estagiários. Essa contratação abrange diversos melhoramentos a curto, médio e longo prazo para as organizações que estiverem conveniadas ao programa. Contudo, por se tratar de um preceito de recrutamento e seleção de pessoas. O PROE ESTÁGIOS segundo a ACIIMA (2017) promove ás empresas a encontrar novos funcionários com talentos, habilidades e competências essenciais para determinada organização, a fim de formar um quadro de profissionais qualificados. O referido programa institui e alimenta a mudança e a inovação dentro das organizações, além de promover às mesmas organizações um vínculo direto para o acompanhamento de avanços tecnológicos e conceituais, difundidos por intermédio de instituição de ensino.

Concerne ao empresário desempenhar sua função social, colaborando para desenvolver as novas gêneses de profissionais com celeridade e dinamismo que as empresas necessitam. Dessa maneira, o estágio não institui vínculo empregatício e não gera encargos trabalhistas A organização que convenciona um ambiente adequado e cômodo à sua complementação educacional, aprontando dentro dos padrões exigidos pelo mercado de trabalho (ACIIMA, 2017).

\section{Mercados}

O ecossistema empreendedor de Imperatriz é composto por micro, pequenas, médias e grandes empresas. Sendo neste cenário, as pequenas e micros empresas incumbidas pela maior parte de geração de trabalho em todo o território (SEBRAE - MA, 2015).

O município de Imperatriz por obter uma localização geográfica estratégica, e por ser o núcleo econômico, político e grande polo universitário da região sul do Maranhão, vem despertando o olhar dos pequenos empreendedores, que procuram investir e atuar, nos diversos campos da economia local bem como: alimentação, vestuário, serviços, tecnológico, entre outros. Entretanto, no ano de 2013, promoveu uma receita para os cofres públicos municipais cerca de 4,3\% do Produto Interno Bruto (PIB) do município de acordo com a secretaria de administração do município.

Todavia, existem ainda vários empreendedores na informalidade, porém, atualmente tem-se uma enorme ruptura dentro desse cenário, e para isto, conta-se com o auxílio do

Organizadores:
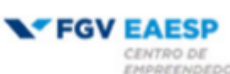

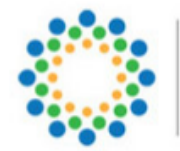

ANEGBPE

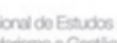

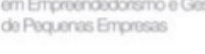
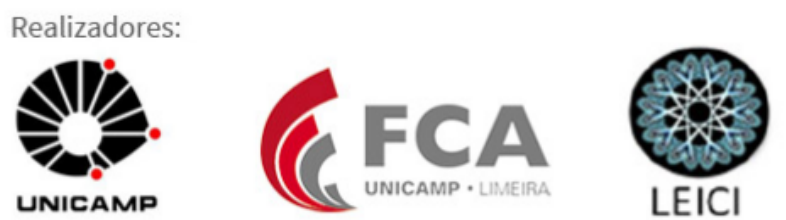
SEBRAE. Ainda no ano de 2013, Imperatriz havia aproximadamente 21.527 empresas formalizadas, destas $93,5 \%$ eram de pequeno porte, equivalente a 20.127 organizações na sua totalidade, concentrando mais de 50.000 colaboradores, com salário médio mensal de 1.576,00 (SEBRAE, 2015).

Estudos feitos neste mesmo sentido, realizado pelo SEBRAE (2015) os setores com maior índice de tributo no município de Imperatriz consistiram no comércio, construção civil e prestação de serviços, que rebateram $54,2 \%$ do volume de recursos somados na cidade, assim o setor de agropecuária obteve correspondência de $24,8 \%$ e a indústria $21 \%$ aproximadamente.

\section{Considerações Finais}

Em síntese, notou-se que a gestão municipal se engaja para proporcionar ao munícipio de Imperatriz condições de estímulos empreendedores. No entanto, observou-se que embora existam esforços direcionados ao fomento empreendedor da gestão pública local, num contexto geral, ainda é pouco difundida a participação municipal dos agentes públicos, bem como das instituições de ensino superior - IES que fundamentalmente tem papel importante dentro do cenário do empreendedorismo.

Analisou-se, além disso, que são abertos leques de discussões em diversos eventos regionais e locais sobre questões empreendedoras com intuito de desenvolver a economia do município, nestes eventos, o SEBRAE que é um alicerce dentro deste ecossistema, juntamente com as instituições de ensino locais (faculdades e universidades) estão na maioria das vezes presentes. Por este motivo, é que na proporção dos embates ou em equivalência aproximada, o poder público precisaria proporcionar mais aliciação por parte das IES nesta conjuntura abordada.

Entretanto, os esforços e os desígnios necessários precisam ser melhores fomentados, a fim de dar concretude aos projetos esboçados com mais celeridade, isto, na intenção de promover ao ecossistema empreendedor do município o desenvolvimento de forma mais eficiente e crescente. Pois, o envolvimento destas mesmas instituições é considerado ainda tímido em relação às amplas discussões que são enaltecidas.

O presente estudo trabalhou com os seis pilares do empreendedorismo aludidos por Isenberg $(2011$; 2013) sendo eles: políticas públicas, capital financeiro, cultura, instituições de suporte, recursos humanos e mercados. Uma vez que o ecossistema empreendedor é composto por estas respectivas variáveis, sendo que a atuação do poder público pode se propagar de forma concomitante dentro dessas mesmas variáveis. No que concerne ao capital financeiro, foi diagnosticado que também há a necessidade de avanços, uma vez que a participação direta encontrada nas análises desta investigação foi a do BNDS em um projeto que demorou cerca de 20 anos aproximadamente para assumir formato e ser efetivado.

Já sobre o aspecto da cultura, foi percebido que o município obteve algumas inclinações e realizações direcionadas para o empreendedorismo, no entanto, notou-se que desde 2004 (quando foi criado o plano diretor do município) até o presente momento, não houve alterações, o que permite conjecturar que as mudanças progressivas não estão ocorrendo de forma eficiente e eficaz dentro da gestão investigada, com base no escalonamento temporal levantado dos últimos 10 anos.

Por outro lado, instituição de suporte como o SEBRAE, tem destaque dentro deste cenário uma vez que esta vem desencadeando papeis importantes de parceria junto ao poder
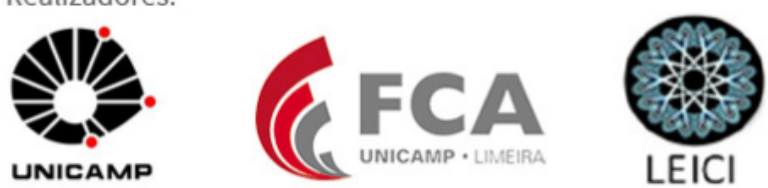
público local. Promovendo cursos e estimulando o empreendedorismo do município de maneira eficaz. Concernente a recursos humanos, o instituto PROE promove as empresas a encontrarem profissionais com capacitação técnica, que possuam habilidades e competências para a ocupação de cargos empresariais e funções administrativas, o que caracteriza numa relevante questão sob o ponto de vista da geração de incitações para o ecossistema empreendedor.

Logo, o mercado de Imperatriz é considerado dinâmico e competitivo, a economia da cidade é tida como a segunda maior do Estado, por isso, o município atrai consideravelmente muitos empreendedores fixados nesse ecossistema. Portanto, há evidencias que comprovam a participação da gestão pública municipal de Imperatriz para o fomento do ecossistema empreendedor, porém, as mesmas apresentaram fragilidades na forma condutora do processo.

\section{Referências}

ACIIMA. Associação Comercial Industrial de Imperatriz Maranhão. Disponível em: $<$ http://www.aciima.com.br/>. Acesso em: 18 de Abril de 2017.

AUTIO. Entrepreneurial innovation: The importance of context. Research Policy, v. 43, n. 7, p. 1097-1108, 2014.

BARDIN, L. Análise de conteúdo. São Paulo: Edições 70, 2011.

BICKMAN, L.; ROG, D. J.; HEDRICK, T. E. Applied research design: a practical approach. In: Bickman, L.; Rog, D. J. (ed.) Handbook of applied social research methods. Thousand Oaks: Sage Publications, 1997. p.05-37.

COHEN, B. Sustainable Valley Entrepreneurial Ecosystem. Business Strategy and the Environment. v. 15, n. 1, p. 1-14, Jan-Fev 2006.

ETZKOWITZ, Henry. Reconstrução Criativa: Hélice tripla e inovação regional. Revista Inteligência Empresarial. Jun, 2005.

FAPEMA, Fundação de Amparo à Pesquisa e ao Desenvolvimento Científico e Tecnológico do Maranhão. 2011. Disponível em:< http://www.fapema.br $>$. Acesso em: 19 de Abril de 2017.

FIEMA, Federação das Indústrias do Estado do Maranhão. Comitê Socioeconômico. Disponível em: $<$ http://www.fiema.org.br/>. 2012. Acesso em: 18 de Abril de 2017.

FRANKLIN, Adalberto. Breve História de Imperatriz. Imperatriz/MA: Ética, 2005.

GOVERNO DO MARANHÃO. Distrito Industrial. 2014. Disponível em: $<$ http://www2.ma.gov.br/index.php/tag/industria-comercio/> Acesso em: 19 de Abril de 2017.

HENREKSON, M., Stenkula, M., Henrekson, M., \& Stenkula, M. 2010. Entrepreneurship and public policy, (804). < http://doi.org/10.1007/978-1-4419-1191-9>

HISRICH. P. Entrepreneurship, intrapreneurship and venture capital: the foundations of economics renaissance. Lexinton: Lexinton Book, 1986.

HOWKINS, J. The mayor's commission on the creative industries. Em: HARTLEY, J. (Ed), Creative Industries. London: Blackwell, 2005. p.117-125.
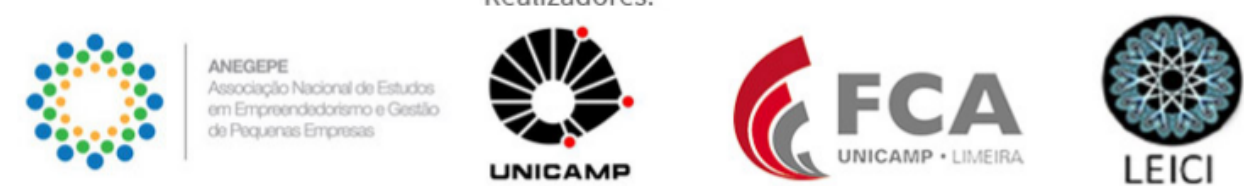
IBGE, Instituto Brasileiro de Geografia e Estatística. Censo populacional 2010. Disponível em <http://www.ibge.gov.br/home/mapa_site/mapa_site.php\#populacao $>$. Acesso em: 06 de Abril de 2017.

IFC. INTERNATIONAL FINANCE CORPORATION. Stakeholder Engagement: a good practice handbook for companies doing business in emerging markets. Washington D.C.: International Finance Corporation, 2007.

IMIRANTE, Imperatriz. Cooperação Técnica. 2017. Disponível em: $<$ http://imirante.com/mobile/imperatriz/noticias/2017/01/30> Acesso em: 18 de Abril de 2017.

ISENBERG, D. J. How to start an entrepreneurial revolution. Harvard Business Review 88(6): 40-50. 2010.

How to Foment an Entrepreneurial Revolution. The Babson Entrepreneurship Ecosystem Project. January 11, 2011.

Worthless, Impossible and Stupid: How Contrarian Entrepreneurs Create and Capture Extraordinary Value. Harvard Review Business Press, 2013.

MASON, C.; BROWN R. Entrepreneurial ecosystems and growth oriented Entrepreneurship. 2014.

MORAES, R. Análise de conteúdo. Revista Educação, Porto Alegre, v. 22, n. 37, p. 7-32, 1999.

NECK, H.M.et al. An entrepreneurial system view of new venture creation. Journal of Small Business Management, v. 42, n. 2, p. 190-208, 2004.

O PROGRESSO, Jornal do Estado do Maranhão. Lei Geral das MPEs. Edição 2012. Disponível em: $<$ http://oprogressonet.com/cidade/prefeito-madeira-destaca-que-ja-foramcriadas-3700-micro-e-pequenas-empresas-em-imperatriz-desde-aprovacao-da-lei-geral-dasmpes/12345.html> Acesso em: 12 de Abril de 2017.

LIU, H. e JIANG, Y. Technology transfer from higher education institutions to industry in China: nature and implications. Technovation 21(3), 175-188. 2001.

PLANO DIRETOR MUNICIPAL. Imperatriz - MA. Lei complementar $\mathbf{n}^{0}$ 02/2004. Julho de 2004.

PORTER, M. E., Sachs, J. D., Cornelius, P. K., MacArthur, J. W., MacArthur, J., \& Vasquez, D. 2002. Executive Summary: Competitiveness and Stages of Economic Development. In P. K. Cornelius \& J. W. Mcarthur (Eds.), Global Competitiveness Report 2001 - 2002. New York: Oxford University Press.

E. \& KRAMER M. R. "The Big Idea: Creating Shared Value, Rethinking Capitalism", Harvard Business Review. January-February 2011. v 89 Issue 1/2, pp.62-77.

SEBRAE, MA. 2015. Disponível em: <http://www.sebrae.com.br/>. Acesso em: 18 de Abril de 2017. 
SEBRAE. Participação das Micro e Pequenas Empresas na Economia Brasileira. 2015. Disponível em: $<$ https://www.sebrae.com.br/Sebrae/Portal\%20Sebrae/Estudos $\% 20 \mathrm{e} \% 20$ Pesquisas/Participaca o\%20das\%20micro\%20e\%20pequenas\%20empresas.pdf $>$ Acesso em: 18 de Abril de 2017.

Paraná. Mapeamento dos ecossistemas de Startups do Paraná. Unidade de Negócios Competitivos - Projeto Startups. 2015.

SCHUMPETER, J. O Fenômeno Fundamental do Desenvolvimento Econômico. In A Teoria do Desenvolvimento Econômico. Rio de Janeiro: Nova Cultural, 1985. 1934.

. The Theory of Economic Development. Cambridge, MA: Harvard University Press,

STAM. E. Entrepreneurial Ecosystems and Regional Policy: A Sympathetic Critique, European Planning Studies, 23:9, 1759-1769, 2015.

TRIBUNA. Licitações municipais: Lei 123/2006 e seus complementos. 2017. Disponível em: $<$ https://tribunadebequimao.wordpress.com/2017/02/10/licitacoes-municipais-ja-podembeneficiar-mpes-afirma-presidente-do-cde-do-sebrae/> . Acesso em: 18 de Abril de 2017.

VERGARA, S. C. Projetos e relatórios de pesquisa em administração. 3.ed. São Paulo: Atlas, 2000.

WEF (World Economic Forum). The Global Competitiveness Index 2014-2015 rankings and 2013 comparisons: Table 3. 